\title{
Effects of Isradipine on Induced-Parkinson's Disease in Rats
}

\author{
Gholamreza Komeili,"* and Farzaneh Farajian-Mashhadi ${ }^{2}$ \\ ${ }^{1}$ Department of Physiology, Faculty of Medicine, Zahedan University of Medical Sciences, Zahedan, IR Iran \\ ${ }^{2}$ Department of Pharmacology, Faculty of Medicine, Zahedan University of Medical Sciences, Zahedan, IR Iran \\ "Corresponding author: Gholamreza Komeili, Department of Physiology, Faculty of Medicine, Zahedan University of Medical Sciences, Zahedan, IR Iran, E-mail: \\ rkomeili@gmail.com
}

Received 2015 January 17; Accepted 2015 November 16.

\begin{abstract}
Background: Parkinson's disease is the second most common neurodegenerative disease in developed countries. Recent studies have showed that there is a relation between neuron loss in Parkinson's disease and L-type calcium channel activity in pars compacta of substantia nigra. Therefore, it seems that calcium channel blockers can effect on this disease.

Objectives: In this study, we evaluate the protective and therapeutic effects of isradipine on experimental Parkinson's model in rats. Materials and Methods: In this experimental study, 63 rats were allocated randomly in seven group including: intact, control, sham operated, lesion and lesion treated by $0.1,0.2$ or $0.4 \mathrm{mg} / \mathrm{kg}$ dosage of isradipine. L-type calcium channel blocker, isradipine was subcutaneously injected to treated rats in the doses of $0.1,0.2$ and $0.4 \mathrm{mg} / \mathrm{kg} /$ day, for four weeks, starting the day after a unilateral nigrostriatal 6-hydroxy dopamine (6-OHDA) lesion. Rotational tests with apomorphine and rigidity tests were conducted on all animal groups one week before the lesion experiments and four weeks after.

Results: Administration of isradipine (0.1, 0.2 and $0.4 \mathrm{mg} / \mathrm{kg} /$ day for 4 weeks) decreased mean of rotation number and muscular rigidity score significantly compared with control group $(\mathrm{P}<0.05)$.

Conclusions: This study showed that isradipine has a therapeutic effect in a dose dependent manner on Parkinson's disease in rats.
\end{abstract}

Keywords: Isradipine, Parkinson Disease, Rat

\section{Background}

Idiopathic Parkinson's is a progressive neurodegenerative disorder characterized by a loss of dopaminergic neurons in substantia nigra pars compacta (SNc) and a decline of dopamine (DA) in striatum [1]. Age is a major risk factor for the development and progression of Parkinson's disease (PD). Aging affects many cellular processes that predispose Parkinson-like neurodegeneration [2]. Parkinson's disease is the second most common neurodegenerative disease in developed countries [3]. The incidence is similar worldwide, with the prevalence increasing in proportion to regional increases in population longevity with more than $1 \%$ affected over the age of 65 years and more than $4 \%$ of the population affected by the age of 85 years [4]. In most instances, PD is multifactorial, likely arising from a combination of polygenic inheritance, environmental exposure and gene-environment interactions. Approximately $20 \%$ of patients with PD report a familiar history of the disease and the monogenic form of this disease is relatively rare [4].

Early disease can be treated with levodopa, DA agonists, anticholinergics and monoamine oxidase inhibitors [5]. Nothing is known to slow the progression of the disease, making the identification of potential neuroprotec- tive agents of great clinical importance [6]. The mechanisms responsible for the preferential loss of DA neurons in PD have been debated for decades. A widely held theory implicates DA itself, suggesting that oxidation of cytosolic DA(and its metabolites) lead to the production of cytotoxic free radicals [3].

There is evidence that an increase in intracellular calcium causes neuronal death, as well as oxidative stress, mitochondrial dysfunction and progression of cytotoxicity [7]. It is clear that 6-hydroxy dopamine and 1-methyl4-phenyl-1, 2, 3, 6-tetrahydopyridine (MPTP) disrupts mitochondrial functions, and they do so through different mechanisms [6]. Experimental evidence and case-control studies suggest that dihydropiridine calcium channel blockers may protect against Parkinson's disease, especially in older persons and may also reduce the mortality rate in $\mathrm{PD}$ [8]. One potential target for neuroprotective therapies in PD is the L-type calcium channel with a Cav1.3 pore-forming subunit [6]. It seems that calcium channel blockers can insert protective effects in neurodegenerative diseases, such as PD [9]. Therefore, it is probable that with reduced calcium entry a decline in the noxious effects of 6-hydroxy dopamine in Parkinson's can be induced.

Isradipine is a specific L-type calcium channel antago- 
nist that is used for hypertension and intracranial hemorrhage [10]. Recent studies have shown that isradipine has a neuroprotective effect in the animal model of PD [6, 7]. Regarding the role of calcium in the pathogenesis of PD, in this study we investigate the effects of isradipine in the animal Parkinson's model in rats.

\section{Objectives}

In this study, we evaluate the protective and therapeutic effects of isradipine on experimental Parkinson's model in rats.

\section{Materials and Methods}

In this experimental study, male Wistar rats (Pasture institute of Iran) weighing 260 - $310 \mathrm{~g}$ were housed in individual cages under standard laboratory conditions $\left(22 \pm 2^{\circ} \mathrm{C}\right.$, $45 \pm 5 \%$ of humidity and a 12 hours light-dark cycle) with ad libitum access to food and water. Following two weeks of adaptation, experiments started at 10 am every day. All experiments were approved by the ethical committee of the Zahedan University of Medical Sciences. Isradipine and apomorphine hydrochloride hemihydrate were purchased from Sigma (French) Company. This study was carried out on 63 male Wistar albino rats $(260$ - $310 \mathrm{~g})$, which were allocated randomly in seven groups, including: intact, control, sham operated, lesion, and lesion treated by $0.1,0.2$ or $0.4 \mathrm{mg} / \mathrm{kg}$ dosage of isradipine. Inclusion criteria included: rats that showed net rotation less than $30 \mathrm{cy}-$ cles/hour after i.p. $2.5 \mathrm{mg} / \mathrm{kg}$ injection of apomorphine. Rotational tests with apomorphine and muscle rigidity tests were conducted in all groups one week before and at end of the experiments [11].

Parkinson induction and 6-OHDA (6-hydroxy dopamine) lesion: Animals were anesthetized with an i.p. (intraperitoneal) injection of ketamine hydrochloride $(60 \mathrm{mg} / \mathrm{kg})$ and xylazine $(10 \mathrm{mg} / \mathrm{kg})$ and placed in stereotaxic apparatus (Narishige sp-5, Japan). Unilateral cannulation in striatum were conducted in accordance with $\mathrm{AP}=4.8, \mathrm{ML}=1.6$ and $\mathrm{DV}=8.2$, relative to bregma [12]. SNc lesions were performed by infusion of 6-OHDA $(4 \mu \mathrm{L}$ saline with $1 \%$ acid ascorbic and 6-OHDA with $2 \mu \mathrm{g} / \mu \mathrm{L}$ for 4 minutes) with an injection cannula, which was left in place for $2 \mathrm{~min}$ before removal. The control group received a neurotoxin solvent, the sham operated group received 6-OHDA and then di-methyl sulphoxide 15\% (isradipine solvent, DMSO 15\%) subcutaneously for four weeks. Treated groups received $0.1,0.2$ or $0.4 \mathrm{mg} / \mathrm{kg} /$ day isradipine subcutaneously one hour before lesion and then daily after lesion for 4 weeks.
Rotational behavioural testing: Motor asymmetry was evaluated through body rotation induced by apomorphine hydrochloride (Sigma, $2.5 \mathrm{mg} / \mathrm{kg}$, i.p.) during 60 minutes follow-up monitoring by observation. The animals were placed in a Plexiglas cylindrical box $(33 \mathrm{~cm} \mathrm{D,} 25$ $\mathrm{cm} \mathrm{H}$ ). In parkinsonian animals, contralateral lesion rotation was encountered as positive and epsilateral lesion rotation as negative. Rotational asymmetry was expressed as net contralateral (contralateral minus epsilateral) rotation per hour [11]. This test was performed for all animals one week before and at the end of the experiments.

Muscle rigidity test (Morpurgo test): Muscle rigidity score was evaluated as described previously [13]. In brief, the animals were placed on a table. If walking and standing was normal, the score $=0$, if the animal was motionless or hardly moved, the score $=0.5$. Furthermore, the right and left hand of the animal was placed on a wooden platform of $3 \mathrm{~cm}$ height, if the animal could not withdrawal its hands within 10 seconds, the score $=0.5$ for each hand. Similar tests were conducted for the right and left hands on a wooden platform of $9 \mathrm{~cm}$ height. If the animal could not withdrawal its hands within 10 seconds, the score $=1$ for each hand. The exception score of each animal with Parkinson's was 3.5 or relative to the severity of the disease, the score was less than 3.5. The score for a normal animal was equal to zero [14].

Statistical analysis: Data were analyzed with KruskalWallis and Mann-Whitney U tests by SPSS-17 software. Results were shown with mean \pm SD and $\mathrm{P}<0.05$ were significant.

\section{Results}

The therapeutic effects of isradipine on the animal model of unilateral Parkinson were considered. Prior to the experiments, there was no difference between the groups for the motor asymmetry test. After the administration of isradipine for 4 weeks ( 0.2 or $0.4 \mathrm{mg} / \mathrm{kg} /$ day), net contralateral rotation decreased significantly in the treated group compared with the lesion and sham operated groups (Table $1, \mathrm{P}=0.01$ ). In the group that received $0.1 \mathrm{mg} / \mathrm{kg} /$ day of isradipine, a number of net contralateral rotation declines were significantly observed in comparison with the lesion group (Table 1, $\mathrm{P}=0.04$ ).

A one way analysis of variance revealed no significant difference in muscle rigidity test score in all groups at the start of experiments, but increased significantly in the lesion, sham-operated and treated with isradipine groups (Table 2). Muscle rigidity score decreased significantly in the group that received isradipine ( 0.2 or $0.4 \mathrm{mg} / \mathrm{kg} / \mathrm{day}$ ) in comparison with the lesion and sham-operated groups 
Table 1. Comparison of Number of Motor Asymmetry ${ }^{\mathrm{a}, \mathrm{b}}$

\begin{tabular}{|c|c|c|}
\hline Groups & Before Surgery & After Surgery \\
\hline Intact & $4 \pm 1.2$ & $3.6 \pm 0.7$ \\
\hline Control & $3.5 \pm 1$ & $4 \pm 1.3$ \\
\hline Sham-operated & $4 \pm 1.5$ & $251.2 \pm 68 \neq$ \\
\hline Lesion & $3 \pm 1.2$ & $254.5 \pm 73 \neq$ \\
\hline Isradipine $0.1 \mathrm{mg} / \mathrm{kg} /$ day & $3.2 \pm 0.9$ & $227 \pm 54.5^{*} \neq$ \\
\hline Isradipine $0.2 \mathrm{mg} / \mathrm{kg} /$ day & $3.6 \pm 0.8$ & $174 \pm 48.5^{* *} \neq$ \\
\hline Isradipine $0.4 \mathrm{mg} / \mathrm{kg} /$ day & $3.8 \pm 0.8$ & $135 \pm 42.2^{* *} \neq$ \\
\hline
\end{tabular}

(Table $2, \mathrm{P}=0.01$ ). Rate of muscle rigidity score also decreased significantly in the group that received isradipine $0.1 \mathrm{mg} / \mathrm{kg} /$ day in comparison with the lesion and shamoperated groups (Table $2, \mathrm{P}=0.03$ ).

Table 2. Comparison of the Muscle Rigidity Test Score in Different Groups ${ }^{\mathrm{a}, \mathrm{b}}$

\begin{tabular}{lcc}
\hline Groups & Before Surgery & After Surgery \\
\hline Intact & $0.1 \pm 0.04$ & $0.1 \pm 0.04$ \\
Control & $0.1 \pm 0.05$ & $0.1 \pm 0.05$ \\
\hline Sham-operated & $0.1 \pm 0.07$ & $3.5 \pm 0.9 \neq$ \\
\hline Lesion & $0.1 \pm 0.06$ & $3.5 \pm 1.2 \neq$ \\
\hline Isradipine $0.1 \mathrm{mg} / \mathbf{k g} /$ day & $0.1 \pm 0.06$ & $2.9 \pm 0.9^{*} \neq$ \\
\hline Isradipine $0.2 \mathrm{mg/kg/day}$ & $0.1 \pm 0.07$ & $2.1 \pm 0.7^{* *} \neq$ \\
\hline Isradipine $\mathbf{0 . 4} \mathbf{~ m g / k g / d a y ~}$ & $0.1 \pm 0.06$ & $1.5 \pm 0.6^{* *} \neq$ \\
\hline
\end{tabular}

${ }^{\mathrm{a}}$ Values are expressed as mean $\pm \mathrm{SD}$.

${ }^{\mathrm{b}}\left(\mathrm{N}=9,{ }^{*} \mathrm{P}=0.03,{ }^{* *} \mathrm{P}=0.01\right.$ in comparison with the lesion and sham-operated groups, $\neq \mathrm{P}=0.001$ in comparison with pre-surgery observations in the same group)

\section{Discussion}

The present study shows that administration of isradipine can significantly decrease net contralateral rotation after apomorphine. Furthermore, muscular rigidity score decreased significantly after isradipine usage. Therefore, we suggest that isradipine had a therapeutic effect on Parkinson's induced with 6OHDA in a dose dependent manner. It has previously been reported that isradipine has a neuroprotective effect on Parkinson's disease in mice [6]. Furthermore, it has been shown that isradipine decreased involuntary movements in the Parkinson's rat model in a dose dependent manner [11, 15]. Epidemiological studies suggest that calcium channel blockers prevent or slow the progression of AD. These studies have similar results with the present study.

It seems that the mechanism of therapeutic effects of isradipine on Parkinson's disease is related to the diminishing of calcium entry to dopaminergic neurons in substantia nigra, and the reduced sensitivity of these cells to neurotoxins such as 6OHDA [5, 6]. Furthermore, a decrease in calcium entry to these cells caused a reduction in cell metabolism and a delay in apoptosis [7]. Previous studies have shown that pre-treatment with nimodipine (calcium channel blocker) can prevent the toxic effects of MPTP on substantia nigra neurons [16]. 5-HT1A and 5-HT1B receptor agonist can reduce dyskinesia after PD induced with 6OHDA [17], that could be involve in isradipine neuroprotective mechanism. Also, previous study shown that T-type calcium channel involves in PD and inhibition of this channel can reduce locomotor deficits in rat model of PD [18].

This study identified that isradipine (selective L-type calcium channel blocker) had therapeutic effects on Parkinson's disease induced with 6OHDA in rats in a dose dependent mode.

\section{Acknowledgments}

We are grateful to the vice chancellor for research of Zahedan University of Medical Science for their financial support (code: K/17) and the laboratory of physiology staff for their assistance.

\section{Footnotes}

Authors' Contribution: All authors had equal role in design, work, statistical analysis and manuscript writing.

Conflict of Interest: The authors declare no conflict of interest.

Funding/Support: This paper had been done by personal expenses.

\section{References}

1. Gorbatyuk OS, Li S, Sullivan LF, Chen W, Kondrikova G, Manfredsson FP, et al. The phosphorylation state of Ser-129 in human alphasynuclein determines neurodegeneration in a rat model of Parkinson disease. Proc Natl Acad Sci U S A. 2008;105(2):763-8. doi: 10.1073/pnas.0711053105. [PubMed: 18178617].

2. Gorbatyuk MS, Shabashvili A, Chen W, Meyers C, Sullivan LF, Salganik $\mathrm{M}$, et al. Glucose regulated protein 78 diminishes alphasynuclein neurotoxicity in a rat model of Parkinson disease. Mol Ther. 2012;20(7):1327-37. doi: 10.1038/mt.2012.28. [PubMed: 22434142]. 
3. Surmeier DJ, Guzman JN, Sanchez-Padilla J, Schumacker PT. The role of calcium and mitochondrial oxidant stress in the loss of substantia nigra pars compacta dopaminergic neurons in Parkinson's disease. Neuroscience. 2011;198:221-31. doi: 10.1016/j.neuroscience.2011.08.045. [PubMed: 21884755].

4. Bekris LM, Mata IF, Zabetian CP. The genetics of Parkinson disease. J Geriatr Psychiatry Neurol. 2010;23(4):228-42. doi: 10.1177/0891988710383572. [PubMed: 20938043].

5. Fernandez HH. Updates in the medical management of Parkinson disease. Cleve Clin J Med. 2012;79(1):28-35. doi: 10.3949/ccjm.78gr.11005. [PubMed: 22219231].

6. Ilijic E, Guzman JN, Surmeier DJ. The L-type channel antagonist isradipine is neuroprotective in a mouse model of Parkinson's disease. Neurobiol Dis. 2011;43(2):364-71. doi: 10.1016/j.nbd.2011.04.007. [PubMed: 21515375].

7. Surmeier DJ. Calcium, ageing, and neuronal vulnerability in Parkinson's disease. Lancet Neurol. 2007;6(10):933-8. doi: 10.1016/S14744422(07)70246-6. [PubMed:17884683].

8. Pasternak B, Svanstrom H, Nielsen NM, Fugger L, Melbye M, Hviid A. Use of calcium channel blockers and Parkinson's disease. Am J Epidemiol. 2012;175(7):627-35. doi: 10.1093/aje/kwr362. [PubMed: 22387374].

9. Ton TG, Heckbert SR, Longstreth WJ, Rossing MA, Kukull WA, Franklin GM, et al. Calcium channel blockers and beta-blockers in relation to Parkinson's disease. Parkinsonism Relat Disord. 2007;13(3):165-9. doi: 10.1016/j.parkreldis.2006.08.011. [PubMed:17055323].

10. Johnson BA, Ait-Daoud N, Wells LT. Effects of isradipine, a dihydropyridine-class calcium channel antagonist, on Dmethamphetamine-induced cognitive and physiological changes in humans. Neuropsychopharmacology. 2000;22(5):504-12. doi: 10.1016/S0893-133X(99)00116-5. [PubMed: 10731625].

11. Sautter J, Kupsch A, Earl CD, Oertel WH. Degeneration of pre-labelled nigral neurons induced by intrastriatal 6-hydroxydopamine in the rat: behavioural and biochemical changes and pretreatment with the calcium-entry blocker nimodipine. Exp Brain Res. 1997;117(1):111-9. [PubMed: 9386009].

12. Paxinos $\mathrm{G}$, Watson $\mathrm{C}$. The rat brain in stereotaxic coordinates. 6 th ed ed. 12. New York: Academic Press; 2007.

13. Sarkaki A, Alavian SM, Mansouri SMT. A study on straital local electrical potential changes in animal model of parkinson's disease. Iran J Pharm Res. 2004;3(1):80.

14. Morpurgo C. Effects of antiparkinson drugs on a phenothiazineinduced catatonic reaction. Arch Int Pharmacodyn Ther. 1962;137:84-90. [PubMed: 14476206].

15. Schuster S, Doudnikoff E, Rylander D, Berthet A, Aubert I, Ittrich $\mathrm{C}$, et al. Antagonizing L-type Ca2+ channel reduces development of abnormal involuntary movement in the rat model of L-3,4-dihydroxyphenylalanine-induced dyskinesia. Biol Psychiatry. 2009;65(6):518-26. doi:10.1016/j.biopsych.2008.09.008. [PubMed: 18947822].

16. Kupsch A, Gerlach M, Pupeter SC, Sautter J, Dirr A, Arnold G, et al. Pretreatment with nimodipine prevents MPTP-induced neurotoxicity at the nigral, but not at the striatal level in mice. Neuroreport. 1995;6(4):621-5. [PubMed: 7605913].

17. Munoz A, Carlsson T, Tronci E, Kirik D, Bjorklund A, Carta M. Serotonin neuron-dependent and -independent reduction of dyskinesia by 5 HT1A and 5-HT1B receptor agonists in the rat Parkinson model. Exp Neurol. 2009;219(1):298-307. doi: 10.1016/j.expneurol.2009.05.033. [PubMed: 19500572].

18. Tai CH, Yang YC, Pan MK, Huang CS, Kuo CC. Modulation of subthalamic T-type $\mathrm{Ca}(2+)$ channels remedies locomotor deficits in a rat model of Parkinson disease. J Clin Invest. 2011;121(8):3289-305. doi: 10.1172/JCI46482. [PubMed: 21737877]. 